\title{
Roundabout with ESPR
}

\author{
Alvin L. Young
}

Received: 16 November 2009 / Accepted: 16 November 2009 /Published online: 4 December 2009

(C) Springer-Verlag 2009

This January 2010 issue begins our 17th year of publishing Environmental Science and Pollution Research (ESPR). With each year, we have continued to evolve into a truly international peer-reviewed journal, and the numbers of research contributions for publication from the scientific community have continued to increase. In the May 2009 issue, the realignment and reorganization of ESPR was announced (Young and Roos 2009). On 1 May 2009, ESPR adopted Springer's Editorial Manager System. This adoption required the selection and training of nine editors having the full responsibility for manuscript submissions allocated to their discipline/subject area. In addition, to support the new Editorial Manager System, a new Editorial Board of 30 members was established. The scope of the journal did not change, and we have used the previous subject area framework as guidance in the submission process. You will note that the Editors and the Editorial Board are now listed in the back inside cover, and a table of contents for the specific issue is printed on the back cover.

I would like to describe some of the actions, activities and accomplishments that occurred in the past 8 months. Thus, I have titled this editorial "Roundabout with ESPR". The term "roundabout" in this instance, refers to a retrospective review of the activities of ESPR.

Submissions As of 15 November 2009, ESPR's Editorial Manager System had received 256 manuscripts from 46 countries. Ms. Cristina Chua, the Journal's Editorial Office

A. L. Young $(\bowtie)$

A.L. Young Consultants, Inc,

1810 Tranquility Road,

Cheyenne, WY 82009, USA

e-mail: youngrisk@aol.com assistant assists the authors with the submission process and receives, checks and assigns the daily submissions to the Editor-in-Chief. She also provides assistance to referees for the review period and sets the final disposition for papers with the Editor's decisions. As of 15 November, the countries with the most submissions included China (47), Germany (22), India (22), Italy (15), Spain (12), the USA (12), Brazil (9), Portugal (8), Turkey (8), the Republic of Korea (8), Malaysia (7) and Australia (6). The remaining countries varied from one to five submissions. As of 15 November, final decisions had been made on 105 manuscripts with $21(20 \%)$ being accepted for publication and 84 $(80 \%)$ being rejected. The Editor-in-Chief made the majority of the rejections at the time of submission and prior to assignment to an Editor. These rejections were primarily based on the poor quality of the science or on only preliminary results, although some were rejected because they were not within the scope of the journal. The pressure to publish early and often was very apparent for manuscripts received from China, India, Turkey and Malaysia because these countries submitted the majority of manuscripts that were quickly rejected. Every effort was made by the Editors/Editor-in-Chief to explain why the manuscripts were rejected, so the authors could profit from the comments in re-directing their research or/and in improving the quality of the manuscripts.

Peer review and referees The importance of the peer review process was described in the September 2008 issue of ESPR (Newton 2008; Dost 2008). Newton noted that proper peer review validates the scientific findings by impartial referees, and it is a demanding service, often uncompensated, that protects the public from poor information. Moreover, proper peer review allows public confidence in scientific findings and provides a model of 
accountability for our society (Newton 2008). Dost commented that the three general objectives of peer review were to prevent the publication of bad material, improve journal scholarship and improve a manuscript's language and data presentation (Dost 2008). Dost concluded that the ultimate screen of the quality of a manuscript is in the hands of the authors; ideally, the reviewer should only have to validate and perhaps improve good work. Failing that ideal, it is easy for the referee to identify true incompetence and easy to defend such judgment, and thus, poor work is made highly visible and soon disappears (Dost 2008).

Obviously, the core issue for peer review is in identifying competent reviewers (referees). This had become a major crisis for ESPR. Although we require the authors of manuscripts to recommend at least three potential reviewers, our Editors have found that most recommended reviewers refuse to conduct the peer review. In some cases, our Editors have had to identify at least nine potential referees in order to have two or three reviews completed. By necessity, we have changed the time period for a referee to respond in accepting or rejecting to do the peer review. We now asked the potential referee to respond in 5 days. If no response, we send another invitation at the end of that 5 days, and if yet no response after 4 additional days (for a total of 2 weeks), we cancel the request and seek another referee. If the referee accepts the task, we ask for the review to be conducted within 14 days. Note that of the 256 manuscripts submitted since 1 May (through 15 November 2009), 151 remained without a final decision. Much of the delay in reaching a final decision can be attributed to the failure in not having the required two or three peer reviews. An inordinate amount of time is lost in identifying, accepting, and in conducting the peer review. An intermediate decision to revise (minor or major) also requires time for the authors to complete the requested revision.

To facilitate for the Editors the selection of qualified referees, we have been building a referee database. It is my opinion that any scientist that publishes in a peer-reviewed journal has the obligation of serving as a referee. Newton stated it best: "Peer review must become an important activity in academic job description and rewards. Failures of peer review are seldom the fault of editors, whose efforts in soliciting competent reviewers are often frustrated" (Newton 2008). In preparation for the implementation of Editorial Manager, and with the help of Almut B. Heinrich, we retrieved data on about 800 active researchers, authors and former referees to begin building that necessary database. As our Editors and members of our Editorial Board have continued to identify additional scientists in the past 8 months, the database is growing. Recently, we sent a form to all of the scientists and engineers in our database to update their profiles.
Acceptance of non-peer reviewed materials As ESPR adopted Springer's Editorial Manager System, we were very fortunate to retain the superb support of Almut B. Heinrich. Ms. Heinrich is responsible for the acquisition and coordination of all non-reviewed articles (ABH. scientificjournals@goolemail.com). This includes such materials as editorials, commentaries, conference reports, book reviews and letters to the editor. Ms. Heinrich also assists in cover design and in the disposition of issues through the process of issue building, thus supporting Mr. Holger Frey who oversees all production aspects relevant to the journal.

ESPR publication plans for 2010 For Volume 17, ESPR will be publishing nine issues. The issues for this month (January), February, March and May will be devoted to publishing all the remaining manuscripts in Online First (from the previous Electronic Submission System) and the manuscripts handled and accepted since May 2009 by the Editorial Manager System. The remaining five issues of Volume 17 (June, July, August, September and November) will be constituted on the basis of "first accepted, first published".

Publication ethics Proper peer review must be free of emotional involvement, prejudice toward certain outcomes or personal agendas other than rigorous science; advocacy or philosophy toward any related issue leads to major judgmental problems. As the Editor-in-Chief I have the responsibility for addressing specific problems such as fraud, poor quality, plagiarism, uninvolved authors and double publication of the same data. Increasingly, I am identifying such problems. Universities and research institutions are highly competitive for research funding. The pressure to publish eye-catching papers in prestigious journals can all too often foster shallowness in research, i.e. poor quality (Newton 2008). Since the number of publications by an author can contribute to institutional advancement and recognition, double publication of the same date is occurring. Our Editors and Referees are requested to use the direct access to MEDLINE and Google Search implemented in the Editorial Manager. The database MEDLINE contains millions of published articles. Through MEDLINE and Google Search it is relatively easy to identify duplicate publications. Three times in the past few months, I have had to confront authors about such duplications. For guidance on the appropriate actions, I have sought advice from the Committee on Publication Ethics (COPE). COPE is a forum for publishers and editors of peer-reviewed journals to discuss issues related to integrity of work submitted to or published in their journals. It supports and encourages editors to report, catalogue and instigate investigations into ethical problems in the pub- 
lications process (http://publicationethics.org). I have also sought advice from members of our Editorial Board representing the countries where the authors conducted their research and prepared their manuscripts.

Conclusion This is an exciting time for environmental science. Almost all of the nations are supporting basic environmental and ecological research (fundamental) as reliable sources of knowledge for environmental policy and decision-making. The sharing of that knowledge through publication in peer-reviewed journals such as ESPR is critical. I encourage your continued support of ESPR as a journal for publication of your research.
Acknowledgement I would like to acknowledge the outstanding support of Paul Roos, Editorial Director for Springer's Environmental Sciences, and his truly excellent staff members Monika Bechtold and Claudia Schiffers. I would also like to acknowledge the advice and assistance provided by our new Consulting Editor, Professor Walter Giger.

\section{References}

Dost FN (2008) Peer review at a crossroads - a case study. Environ Sci Pollut Res 15:443-447

Newton M (2008) More on peer review: quality control for a costly product. Environ Sci Pollut Res 15:439-442

Young AL, Roos P (2009) The realignment and reorganization of ESPR. Environ Sci Pollut Res 16:243-247 